Protestantismo em Revista é licenciada sob uma Licença Creative Commons.

http://dx.doi.org/10.22351/nepp.v43i2.3066

\title{
A performance da fé nas celebrações religiosas neopentecostais
}

\author{
The performance of faith in Neo-pentecostals religious celebrations
}

Ana Rafaela Sales de Araújo*

Bruno Carvalho Meneses**

\begin{abstract}
Resumo
O presente artigo discute as formas de atuação do neopentecostalismo no Brasil, enquanto fenômeno midiático. Elegeu-se como objeto de estudo a Igreja Mundial do Poder de Deus e o seu fundador, Valdemiro Santiago. Aborda-se brevemente a história do neopentecostalismo no Brasil, bem como suas inovações. Dentre essas inovações, verifica-se a necessidade das igrejas em usar a mídia televisiva para a evangelização e o surgimento de novas formas de experiência do sagrado no processo de midiatização da fé. Em seguida, promove-se uma breve análise da Igreja Mundial do Poder de Deus, do apóstolo Valdemiro e de suas performances na mídia. Como conclusão, verifica-se que a sociedade brasileira caminha cada vez mais em direção a novas formas de religiosidade e de contato com o sagrado, e que a mídia foi a mola propulsora responsável pelo desenvolvimento desta nova religiosidade denominada midiática.
\end{abstract}

\section{Palavras-chave}

Neopentecostalismo brasileiro. Igreja Mundial do Poder de Deus. Televisão na evangelização.

\begin{abstract}
The present paper discusses the forms of action of neopentecostalism in Brazil, as a media phenomenon. The World Church of the Power of God and its founder, Valdemiro Santiago, were choose as object of study. The history of neopentecostalism in Brazil, as well as its innovations, is briefly discusses. Among these innovations, there is a need for churches to use television media for evangelization and the emergence of new forms of experience of the sacred in the process of mediatization of faith. Following is a brief analysis of the World Church of God's Power, the apostle Valdemiro and his performances in the media. As a conclusion, it turns out that Brazilian society is increasingly moving towards new forms of religiosity and contact with the sacred, and that the media was the driving force responsible for the development of this new religiosity called media.
\end{abstract}

[Texto recebido em julho de 2017 e aceito em janeiro de 2018, com base na avaliação cega por pares realizada por pareceristas ad hoc]

* Bibliotecária Documentalista da Universidade Federal do Ceará. Graduada em Biblioteconomia (UFC). Especialista em Gestão Pública (UNILAB). Mestranda em Biblioteconomia (UFCA). E-mail: rafaela@ufc.br

** Graduando em Biblioteconomia (UFC). E-mail: bruno.dc91@gmail.com 


\section{Keywords}

Brazilian Neopentecostalism. World Church of the Power of God. Television in evangelistic work.

\section{Introdução}

Neste artigo, busca-se analisar a atuação das denominações neopentecostais como fenômeno social e midiático, visto que a religiosidade é afetada pelo fiel, pela denominação (via atuação do líder religioso) e pela mídia, provocando novas formas de experiência religiosa.

Por conseguinte, aborda-se a terceira onda pentecostal, chamada neopentecostalismo, traçando um breve histórico, bem como seu contexto no Brasil, as inovações que as denominações neopentecostais colocaram em prática, e como essas inovações, dentre elas, o uso dos meios de comunicação de massa, destacando-se o uso da televisão, provocaram modificações na experiência religiosa do fiel para com Deus.

Pode-se perceber que essas inovações fizeram com que as denominações religiosas utilizassem cada vez mais os meios de comunicação, seja para levar a mensagem do evangelho ou para atrair mais fiéis. Essa recorrente utilização aumenta a visibilidade da experiência divina, tornando o ritual religioso um espetáculo.

Analisa-se ainda as relações entre líderes e fiéis da Igreja Mundial do Poder de Deus, elegendo-a por conta de sua visibilidade na mídia e por suas variadas formas de atrair fiéis, além do modo interessante pelo qual o apóstolo Valdemiro Santiago, fundador da igreja, conduz o seu "rebanho".

Neste artigo, atenta-se também para a flexibilidade que a mídia promove entre as denominações, provocando mudanças como a criação de novas igrejas e/ou ministérios, pois, desta forma, o fiel tem possibilidades de escolha, existindo uma denominação adaptada para cada fiel, possibilitando assim que o novo participante não precise mudar seu visual, seu gosto musical, um exemplo é a igreja Bola de Neve, em que o púlpito é uma prancha de surfe.

Diante do exposto, as práticas religiosas adquirem cada vez mais o caráter de espetáculo midiático, ocorrendo uma forma de hibridação entre sagrado e profano. Assim, o que anteriormente era inconcebível através dos "mass Media" adquire um novo sentido. A cada dia surge uma nova igreja midiática, cujo líder é um artista, uma verdadeira estrela e, os seus fiéis, seus fãs.

\section{A terceira onda pentecostal: neopentecostalismo}

O neopentecostalismo é um movimento que se caracteriza pela presença de um líder carismático e centralizador que exerce uma ideologia perante a massa de fiéis. As 
igrejas que aderem a este movimento agem de forma autônoma e libertária em todos os aspectos (liturgia, teologia, louvor). Possuem liturgias inovadoras que se adequam conforme o pedido do "freguês", ou melhor, de seus adeptos. As igrejas que fazem parte deste movimento oferecem um "cardápio" diversificado para cada dia da semana, por exemplo: "domingo da glória de Deus", "clamor pelo crescimento financeiro", "terça-feira do milagre urgente", "quinta-feira das portas abertas" e conquistam também grupos de todos os tipos (surfistas, roqueiros, pagodeiros, atletas, pobres, ricos, homossexuais).

Existem várias tipologias das formações pentecostais no Brasil. Aborda-se, neste artigo, o "pentecostalismo clássico", neopentecostalismo e o pentecostalismo dividido em ondas, pois devido às várias nomenclaturas e tipologias que o pentecostalismo possui, não há como analisá-lo homogeinamente. Desta maneira, dar-se-á enfoque à forma de divisão do movimento pentecostal em ondas, ideia originária dos norte-americanos. Segundo Velasques Filho, o pentecostalismo se divide em duas fases: os primeiros anos do século XX, referindo-se ao que chamamos 'pentecostalismo clássico', e a década de 1960, quando ocorreu o surgimento do neopentecostalismo. ${ }^{1}$

Já para Freston, o pentecostalismo brasileiro pode ser entendido por meio de três ondas de implementação de igrejas: a primeira onda começa na década de 1910, com a chegada da Congregação Cristã, no Estado de São Paulo, e da Assembleia de Deus em 1911, no Estado do Pará, fundadas respectivamente, pelo italiano Luigi Francescon e pelos missionários suecos Daniel Berg e Gunner Vingrer; a segunda onda pentecostal ocorre entre as décadas de 1950 e início de 1960, na qual o movimento pentecostal se fragmenta e a relação com a sociedade se torna dinâmica, três grandes grupos, em meio a dezenas de menores, surgem: a Igreja do Evangelho Quadrangular, em 1951; a Igreja Evangélica Pentecostal O Brasil para Cristo, em 1955; a Igreja Pentecostal Deus é Amor (IPDA), em 1962, fundadas respectivamente pelos missionários: Harold Edwin Willians, Manoel de Mello e David Martins Miranda, o contexto dessa proliferação acontece no Estado de São Paulo; a terceira onda começa no final da década de 1970 e ganha destaque na década de 1980. Dentre suas principais representações surgem: a Igreja Universal do Reino de Deus (IURD), em 1977; a Igreja Internacional da Graça de Deus (IIGD), em 1980, fundadas respectivamente pelo Bispo Edir Macedo e pelo missionário Romildo Ribeiro Soares. ${ }^{2}$ Essa proliferação de igrejas pentecostais tem como cenário o Estado do Rio de Janeiro.

Pode-se compreender a terceira onda como sendo o período do neopentecostalismo que surgiu em meados da década de 1970 e se perpetua até os dias de

1 VELASQUES FILHO, Prócoro. Declínio do cristianismo tradicional e ascensão das religiões do espírito. In: MENDONÇA, Antônio Gouvêa; VELASQUES FILHO, Prócoro. Introdução ao protestantismo no Brasil. 2. ed. São Paulo: Loyola, 2002. cap. 10.

2 FRESTON, Paul. Breve história do pentecostalismo brasileiro. In: ANTONIAZZI, Alberto et al. Nem anjos nem demônios: interpretações sociológicas do pentecostalismo. Petrópolis: Vozes, 1994. p. 67-96. 
hoje, crescendo explosiva e intensamente, conquistando cada vez mais adeptos de todas as camadas sociais brasileiras.

Pignatari traça características do movimento neopentecostal no Brasil, caracterizando-o como: "seus líderes são pregadores nacionais; caracterizam-se no plano teológico por enfatizar a guerra espiritual contra Satanás, por difundir a crença de que o cristão deve ser próspero (Teologia da Prosperidade), a cura física e emocional [...]". ${ }^{3}$

Os líderes do movimento neopentecostal estimulam o fiel a buscar a prosperidade ao invés da graça de Deus, pregam que as pessoas devem colocar Deus na parede e exigir bênçãos sem medida e que o ser humano deve conquistar "o melhor desta terra" o que, muitas vezes, equivale a carros novos, mansões com piscina e uma gorda conta bancária.

Com relação às práticas litúrgicas, as denominações neopentecostais trabalham mais com liturgias baseadas em técnicas de autoajuda do que precisamente com a Bíblia, não são rígidas no que diz respeito a "usos e costumes", diferentemente das denominações ditas tradicionais, as quais prezam a liturgia baseada na Bíblia. Outras características dos grupos neopentecostais: seus rituais são espetaculosos e não dispensam curas milagrosas e exorcismos, há também o momento da glossolalia, onde os fiéis, que são batizados no Espírito Santo, começam a falar a língua dos anjos, assim como foi em Pentecostes, ${ }^{4}$ outra característica deste movimento, conforme Souza, "suas orações fogem do modelo suave e assumem o estilo da ousadia reivindicativa 'autorizada' pela palavra de Deus". ${ }^{5} \mathrm{~A}$ barulheira está presente no confronto com os espíritos malignos e nas expressões de adoração (Glória a Deus e Aleluia) que são pronunciadas em voz elevada, acrescida das palmas que acompanham as canções.

Algumas dessas igrejas mantêm forte presença na mídia televisa e radiofônica e algumas até possuem uma própria rede de televisão, como é o caso da IURD, fundada pelo bispo e empresário Edir Macedo, proprietário da Central Record de Comunicação Rádio e Televisão Record S/A, a qual engloba a Rádio Record, Rede Record de Televisão, adquiridas pelo bispo em 1989, e a mais nova emissora de televisão, Record News, fundada em 2007.

3 PIGNATARI, Rosa Malena. Templos midiáticos: a comunicação como instrumento de propagação da fé. In: CARDOSO, Clodoaldo Meneguello (Org.). Diversidade e igualdade na comunicação: coletânea de textos do Fórum da Diversidade e Igualdade: cultura, educação e mídia. Bauru: FAAC/Unesp, 2007. p. 7. Disponível em: <http://www2.faac.unesp.br/publicacoes/anais-comunicacao/textos/12.pdf>. Acesso em: 28 jul. 2017.

4 O dom de falar línguas estranhas, que desde o início do pentecostalismo constitui uma de suas principais marcas distintivas, remete ao episódio bíblico de pentecostes, relatado no livro de Atos capítulo 2, em que o Espírito Santo, no quinquagésimo dia da ressurreição de Cristo, teria se manifestado aos apóstolos por meio de línguas de fogo.

5 SOUZA, Alexandre Carneiro de. A inserção do pentecostalismo no protestantismo brasileiro. In: SOUZA, Alexandre Carneiro de. Pentecostalismo: de onde vem, para onde vai? Viçosa: Ultimato, 2004. p. 129. 


\section{As inovações do neopentecostalismo}

Com o surgimento do neopentecostalismo, vieram as interferências midiáticas. Uma forma encontrada pelas igrejas desse novo segmento de arrebanhar mais fiéis e conseguir se enquadrar em um espaço onde a indústria cultural tem um peso significativo refere-se ao uso de revistas, internet, redes de rádio e televisão, constituindo-se como o grande diferencial desse segmento religioso.

No centro dessa corrida midiática religiosa, em relação ao segmento neopentecostal, cabe destacar três igrejas de maior visibilidade: Igreja Renascer em Cristo (IRC), Igreja Universal do Reino de Deus (IURD) e a Igreja Internacional da Graça de Deus (IIGD). Todas as igrejas com líderes reconhecidos nacional e internacionalmente através de programas televisivos que pregam principalmente a prosperidade e a cura.

Para Paegle, "o espetáculo que os evangélicos proporcionam ocorre tanto no espaço midiático, especialmente o televisivo, quanto na ocupação do espaço público". ${ }^{6}$ Percebe-se claramente isso, uma vez que essas igrejas possuem programas de televisão tanto em canais abertos quanto em canais fechados. Programas esses que dão aos fiéis telespectadores uma sensação de proximidade e individualização, via compartilhamento de problemas e, em alguns casos, usufrui de uma maior interatividade, já que, ao mesmo tempo, ele pode ver o "seu pastor" na tela da TV, contar pelo telefone a sua aflição, compartilhar testemunhos de cura e prosperidade.

Segundo Paegle, "a IURD apresenta-se como o maior exemplo de espetacularização da fé no campo religioso brasileiro".7 Isso porque o seu líder Edir Macedo vem, ao longo dos anos, alcançando uma grande massa de fiéis através dos programas televisivos apresentados na Rede Record, que pertence a ele desde 1989. Esta espetacularização ocorre via eventos grandiosos como a Fogueira Santa de Israel, que acontece duas vezes por ano, e também com cultos que, ao longo da semana, ganham vários epítetos como, culto da libertação espiritual, cura e prosperidade.

Um exemplo desse fenômeno, porém, em outro aspecto se dá na igreja Renascer em Cristo que foi a principal responsável pela consolidação do mercado gospel e também pela realização de shows e festivais de música, além do evento denominado "Marcha pra Jesus", que reúne milhões de fiéis em várias cidades brasileiras.

Além da midiatização da fé através do espetáculo, verifica-se outro tipo de inovação no segmento neopentecostal que vem se destacando como uma doutrina de autoajuda, da prosperidade e da felicidade instantânea, que exige uma proatividade do fiel.

6 PAEGLE, Eduardo Guilherme de Moura. A "McDonaldização" da fé: um estudo sobre os evangélicos brasileiros. Protestantismo em Revista, São Leopoldo, v. 17, p. 86-99, set./dez. 2008. p. 94.

7 PAEGLE, 2008, p. 95. 
Percebe-se também uma mudança em relação aos pastores, já que uma nova geração surge, caracterizada pela presença de líderes que possuem maior grau de escolarização, como por exemplo, Rinaldo Luiz de Seixas Pereira, o pastor Rina, da Bola de Neve Church (BNC) ou o bispo Robson Rodovalho, da Comunidade Evangélica Sara Nossa Terra (CESNT) que demonstram uma modernização no seu discurso, atraindo assim, outro tipo de fiel.

No entanto, o que mais chama atenção é a forma dinâmica como os "novos pastores" lidam com seus fiéis, dando um tratamento diferenciado e específico. Na Comunidade Evangélica Sara Nossa Terra, por exemplo, ocorrem eventos dedicados aos jovens e até mesmo aulas de hip hop, capoeira e funk, e na Bola de Neve Church, cabe destacar, o liberalismo, já que seus fiéis, na sua maioria surfistas e skatistas, não deixam de se tatuar e nem modificaram sua forma de se vestir e de falar. Com esse fenômeno, verifica-se que os fiéis têm mais opções de escolha e podem adorar a Deus à sua medida.

\section{Corrida intensa das igrejas para a televisão}

Com o surgimento dos meios de comunicação de massa, especialmente da televisão, as igrejas têm procurado veicular suas mensagens no meio televisivo, a fim de atraírem mais fiéis e propagar o evangelho em todos os lugares da terra através de possibilidades de cura para os males, mensagens de encorajamento, ensinamentos que busquem promover a importância da vida e do ser humano.

No Brasil, a presença evangélica na televisão teve início na década de 1960 com o programa "Fé por hoje" apresentado pelo pastor Alcides Campolongo da Igreja Adventista. A igreja evangélica que mais investiu na mídia até hoje no Brasil foi a Igreja Universal do Reino de Deus, prova disso foi a aquisição da Rede Record pelo bispo Edir Macedo, em 1953, que contribuiu de forma significativa para o crescimento da igreja dentro e fora do país. Com suas mensagens, consegue atingir não apenas os fiéis, como também outros tipos de público que passam a se identificar com a liturgia da igreja.

A televisão é um meio de comunicação que possibilitou a ultrapassagem das barreiras de espaço e tempo. A presença física do fiel durante o culto não é mais um quesito tão importante, pois atualmente pode-se evangelizar um público bem maior via satélite, por isso, cada vez mais padres e pastores têm buscado veicular suas celebrações na televisão e essa teletransmissão das celebrações se torna mais cômoda para o fiel, pois ele pode assistir o seu pastor favorito na telinha sem precisar sair de casa, além disso, pode "participar do culto" como se estivesse presente fisicamente e pode ter suas bênçãos concedidas, mesmo não participando da experiência religiosa do contato. A televisão funciona como um canal simbólico que possibilita a interligação da pessoa com Deus.

Essa tendência da teletransmissão das celebrações religiosas é bem visível no Brasil, prova disso é a forma como as igrejas procuram adequar seus cultos no molde 
televisivo, fazendo, assim, um cruzamento entre as "imagens de culto e as imagens da mídia" .8

Diante desse contexto, surge uma inquietação por parte dos líderes religiosos: com o advento das igrejas eletrônicas, a experiência religiosa corre o risco de ser reduzida a um mero espetáculo midiático, já que os espaços da TV e o posicionamento das câmeras são ajustados para que o pastor e suas performances corporais sejam facilmente visíveis, deixando de lado a missão primordial das igrejas: perpetuar a fé genuína em Jesus Cristo a todos os povos.

\section{A Igreja Mundial do Poder de Deus e as novas relações entre líderes e fiéis}

Dentre as principais denominações neopentecostais brasileiras, a Igreja Mundial do Poder de Deus (IMPD) apresenta-se como uma alternativa do campo religioso para os fiéis que, descontentes com os resultados negativos provenientes de outras igrejas do mesmo segmento, adotam-na em busca de outras opções religiosas a fim de obterem soluções para os seus problemas.

A IMPD possui algumas características que a diferencia das demais denominações neopentecostais. Em vista disso, analisa-se algumas das principais características da Igreja Mundial do poder de Deus, em virtude de suas estratégias para alcance de fiéis, promover a inserção de várias práticas inéditas nas celebrações religiosas.

A Igreja Mundial do Poder de Deus (IMPD), comandada pelo ex-bispo da IURD Valdemiro Santiago de Oliveira, foi fundada em nove de março de 1998, na cidade de Sorocaba, interior do Estado de São Paulo. No início de sua formação, a igreja contava com apenas dezesseis membros, todavia, em um intervalo de doze anos foram conquistados milhares de fiéis. Atualmente, a denominação possui cerca de 500 templos em quase todo o Brasil, além de vários edifícios espalhados em alguns países da Europa, da América do Sul e da África.

Em pouco tempo, diante do vertiginoso crescimento da igreja, foi preciso alugar um local maior. Então, em junho de 2006, foi inaugurado o Templo dos Milagres, em uma área de 43 mil metros quadrados, situada no bairro do Brás, na cidade de São Paulo.

Diferentemente das principais denominações que compõem o cenário neopentecostal de nosso país - Igreja Renascer em Cristo (Estevam e Sônia Hernandes), Igreja Universal do Reino de Deus (Edir Macedo) e Igreja Internacional da Graça de Deus (R. R. Soares) - os líderes da IMPD estabelecem relações de amizade e companheirismo com os fiéis. Em suas reuniões, Valdemiro Santiago chora de felicidade com o fiel que recebeu a cura, abraça o fiel que foi abençoado, cumprimenta os idosos, os jovens e as

8 KLEIN, Alberto. Mídia e Igreja: contaminações semióticas. In: KLEIN, Alberto. Imagens de culto e imagens da mídia: interferências midiáticas no cenário religioso. Porto Alegre: Sulina, 2006. p. 141-218. 
crianças e fala da sua vida pessoal para os fiéis. Quando um fiel recebe um milagre durante a reunião, Valdemiro o convida para subir ao altar e contar ao público o milagre recebido, o que não acontece nas denominações neopentecostais similares à Mundial do Poder de Deus.

Analisando o formato de culto das denominações neopentecostais anteriormente citadas, percebe-se que há um grande distanciamento entre o líder e o fiel, sobre este assunto, Alberto Klein ressalta:

Na IRC, o culto é em sua essência 'televisiva'. Estevam e Sônia aparecem e
desaparecem, eliminando os cumprimentos aos fiéis na saída da igreja e
fortalecendo sua distância física do público. Alimenta-se tal distância como
na relação entre fã e ídolo. Sônia já admitiu 'achar estranho' ser abordada
no meio da rua para dar autógrafo. A separação nítida entre o palco e a
platéia faz com esta não participe, mas apenas assista e ora se comporte
como auditório de programa de TV. ${ }^{9}$

Esse distanciamento físico, segundo observou Klein, ${ }^{10}$ deve-se ao modo como o espaço para a celebração dos cultos é construído, com a finalidade de transmitir os cultos em canais de televisão. Desta maneira, os fiéis são transformados em meros telespectadores que participam passivamente dos cultos, e os líderes são transformados em apresentadores famosos de programas televisivos.

Outro ineditismo do ministério de Valdemiro Santiago é a cura física dos doentes através do próprio suor do apóstolo Valdemiro. No momento da pregação, o apóstolo enxuga o suor com uma toalhinha e entrega ao fiel que estiver mais próximo dele. Quando o apóstolo caminha entre a multidão, percebe-se uma grande euforia dos fiéis que logo ficam ansiosos para tocar em seu corpo na esperança de receber uma cura. Esse assédio constante advindo da multidão pode ser explicado pelo forte carisma que Valdomiro possui. Carisma este que, somado à aproximação física e emocional aos fiéis, garante a conquista de milhares de adeptos pelo Brasil, e ao redor do mundo.

Com relação à hierarquia sacerdotal, a igreja trabalha com os seguintes cargos, na ordem do maior para o menor: apóstolo, bispo, pastor, obreiro. O líder principal da igreja é o apóstolo Valdemiro Santiago, seguido de sua esposa, a bispa Franciléia, que o auxilia em suas atividades religiosas.

O apóstolo Valdemiro Santiago também é escritor, possui cinco livros publicados pela própria editora da IMPD: O grande livramento, Revelação no altar, Os pensamentos de Deus, Sê tu uma bênção e Lágrimas no deserto, no qual descreve os cinquenta e três dias de sofrimento em que a sede da IMPD, localizada na cidade de São Paulo, foi fechada por intermediação da prefeitura, por causa da poluição sonora que a igreja produzia.

\footnotetext{
9 KLEIN, 2006, p. 181.
}

10 KLEIN, 2006. 
Com relação à presença na mídia, a IMPD possui uma página na web na qual divulga os eventos da própria igreja, vídeos dos testemunhos e milagres que ocorreram durante suas reuniões, no site também estão disponíveis o acesso à TV Mundial, onde é possível assistir ao vivo as celebrações e a rádio Sê tu uma Bênção (98.1 FM), que pode ser ouvida em português ou em espanhol. Os fiéis também podem seguir a igreja no twitter.

A IMPD utiliza-se muito da venda de objetos simbólicos que remetem a passagens bíblicas, como exemplo, podemos citar a "redinha da prosperidade",11 que o apóstolo Valdemiro oferece em troca pede uma oferta de cento e cinquenta e três reais. Para sensibilizar o fiel, o apóstolo fala que quem ajudar com a oferta terá um milagre financeiro em sua vida, realizando, assim, uma espécie de "venda casada do milagre".

Como instituição religiosa, a igreja exerce o compromisso com a obra social através da implantação da Associação Mundial de Assistência Social (AMAS), que tem como objetivo dar assistência às crianças de rua. A AMAS tem como presidente a bispa Franciléia Oliveira e como coordenadora Vera Lúcia Lucas, contando com uma equipe de profissionais voluntários atuantes em diversas áreas.

\section{Considerações finais}

Pode-se notar claramente a mudança e a mesclagem que vem ocorrendo no tocante à relação entre religião e mídia. Não sabemos se os cultos são oferecidos a Deus ou ao ser humano. As "igrejas da mídia" buscam, muitas vezes, chamar a atenção das pessoas para aumentar o IBOPE ou enriquecer. Programam seus cultos com cenários televisivos e focam o "pastor-apresentador", que é altamente aclamado e admirado pelos fiéis.

É interessante notar que, segundo esses líderes, os cultos e os programas religiosos têm o objetivo de propagar o Evangelho de Cristo e levar mensagens de Deus àqueles que necessitam. Esses objetivos são alcançados rapidamente, mas será que essa é a maneira mais apropriada de transmitir a mensagem divina às pessoas? A forma de agir dessas igrejas prega demasiadamente a batalha contra Satanás (Igreja Universal do Reino de Deus), prosperidade (Igreja Apostólica Renascer em Cristo) e a cura (Igreja Internacional da Graça de Deus), alcançando, assim, muitos adeptos.

Dessa complexa relação existente entre religião e mídia na contemporaneidade, destaca-se a grande presença da televisão. Foi devido a ela que os cultos tomaram novas formas. A televisão é um meio de comunicação de massa presente em quase todos os lares e é com base nisto, que as denominações religiosas a enxergam como uma forma altamente eficaz de propagação do evangelho. Com o passar do tempo, as igrejas foram se

11 Representa a história narrada no livro de João capítulo 21, na qual os apóstolos saíram à noite para pescar, mas não conseguiram pescar nada e pela manhã Jesus deu a ordem de lançar a rede ao mar novamente e os discípulos conseguiram pescar 153 peixes, que encheram a rede. 
adequando ao ambiente televisivo e adquiriram novas formas de propagar a fé e de lidar com a experiência do sagrado.

Por fim, observa-se que a sociedade brasileira está marchando cada vez mais em direção a novas formas de religiosidade e de contato com o sagrado, e que a mídia foi a mola propulsora responsável pelo desenvolvimento desta nova religiosidade denominada midiática, da qual a religião não tem como escapar.

\section{Referências}

FRESTON, Paul. Breve história do pentecostalismo brasileiro. In: ANTONIAZZI, Alberto et al. Nem anjos nem demônios: interpretações sociológicas do pentecostalismo. Petrópolis: Vozes, 1994.

KLEIN, Alberto. Mídia e Igreja: contaminações semióticas. In: KLEIN, Alberto. Imagens de culto e imagens da mídia: interferências midiáticas no cenário religioso. Porto Alegre: Sulina, 2006.

PAEGLE, Eduardo Guilherme de Moura. A “McDonaldização" da fé: um estudo sobre os evangélicos brasileiros. Protestantismo em Revista, São Leopoldo, v. 17, p. 86-99, set./dez. 2008.

PIGNATARI, Rosa Malena. Templos midiáticos: a comunicação como instrumento de propagação da fé. In: CARDOSO, Clodoaldo Meneguello (Org.). Diversidade e igualdade na comunicação: coletânea de textos do Fórum da Diversidade e Igualdade: cultura, educação e mídia. Bauru: FAAC/Unesp, 2007. Disponível em:

<http://www2.faac.unesp.br/publicacoes/anais-comunicacao/textos/12.pdf>. Acesso em: 28 jul. 2017.

SOUZA, Alexandre Carneiro de. A inserção do pentecostalismo no protestantismo brasileiro. In: SOUZA, Alexandre Carneiro de. Pentecostalismo: de onde vem, para onde vai? Viçosa: Ultimato, 2004.

VELASQUES FILHO, Prócoro. Declínio do cristianismo tradicional e ascensão das religiões do espírito. In: MENDONÇA, Antônio Gouvêa; VELASQUES FILHO, Prócoro. Introdução ao protestantismo no Brasil. 2. ed. São Paulo: Loyola, 2002. 